\title{
Public Learning Derived from Institutional Learning: The Case Study of the Kelabit Highlands Community Museum Development
}

Meghan Kelly

\author{
Deakin University
}

\begin{abstract}
In this article the author shows how institutional learning can become a site of public pedagogy when conducted on location. This article refers to the 2015 study abroad program for the Kelabit Highlands Community Museum project, located in the Highlands of Borneo, to highlight numerous examples of informal learning for academic, student and community participants based on the five categories of public pedagogy as identified by Sandlin, O'Malley and Burdick (2011). Of particular importance, however, is the public pedagogy that occurred once the study abroad program was complete. Students and academics, invited to assist in the development of the community museum, facilitated the community's own agency in learning as the community learnt from the engagement and adapted this learning to suit their unique cultural requirements. In doing so, this article reveals that not only do study abroad programs enforce the strong intersection of public pedagogy and collective agency, they demonstrate how informal learning can be derived from formal learning.
\end{abstract}

\section{Keywords}

public pedagogy, community, collective agency, study abroad programs

Journal of Public Pedagogies, Number 1, 2016

Published by Public Pedagogies Institute: www.publicpedagogies.net.au

Open Access article distributed under a CC-BY-NC 4.0 license

URL http://jpp.vu.edu.au/

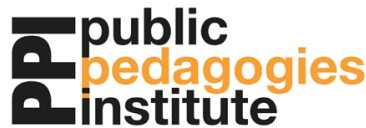


Education literature refers to the differences between institutional and non-institutional, formal and informal learning, moving comfortably between the definitions. Learning that occurs in a study abroad experience has been celebrated as a space of intersection between institutional and non-institutional learning, constructed and situation learning, formal and informal learning (Howard \& Gulawani 2014; Shin Yu, Harris \& Sumner 2006).

Public pedagogy, on the other hand, is defined as learning that occurs outside of the formal learning context. Public pedagogy, as a broad, complex area of research, is limited in its investigation of the intersecting space between formal and informal learning practices. This article examines the study abroad program, namely that of the Kelabit Highlands Community Museum project, to highlight the public pedagogies that occur within the framework of a study abroad construct. It argues that institutional learning, when conducted on location and outside of the 'classroom', becomes a site-enhancing mode of public pedagogy: learning outside the formal, constructed learning environment.

The article will begin with a brief outline of the differences between institutional learning and public pedagogy, identifying study abroad programs as an educational context that sits at the intersection of both fields of study. This will be followed by an overview of the case study example of the Kelabit Highlands Community Museum project, outlining the aims and ambitions of the participating groups. The author will use as a structural framework a summary of the five categories of public pedagogy as defined by Sandlin, O'Malley and Burdick (2011) to demonstrate the many areas of informal learning generated from a study abroad experience. In particular this included the learning that occurred once the academic and student cohort had returned to their home country. Learning did not end on the completion of the study abroad program, and the ongoing legacy was the empowerment to the community who used this knowledge to enhance their own wellbeing as they continued with the project. Community members, adapting their learning to suit their unique cultural environment, were able to continue with the development, demonstrating their collective agency in learning. This project, led by the community yet informed by participants working within the formal framework of the educational system, demonstrates the valuable intersection of institutional and non-institutional learning.

\section{Formal and Informal Learning with Study Abroad Programs}

Institutional modes of learning are defined as learning that occurs in schools and universities; environments that are formally constructed. Commonly referred to as intentional learning, institutional learning is typically evaluated through formal assessment procedures, is classroom or off-campus based and is strongly structured (Younes \& Asay 2003). Hull (1981, p. 65) explains that classroom-centred learning is usually more controlled and controllable, being easier to plan and somewhat predictable. The educator knows what has and must be considered in the classroom by supplying specified readings and materials. Informal learning, a category that includes incidental learning, is typically not classroom based or highly structured and the control of the learning rests in the hands of the learner. Informal learning can still occur in a formal learning environment, however it is defined as a 'byproduct of some other activity', such as interpersonal interaction, through sensing, trial-and-error or learning from others (Younes \& Asay 2003, p. 142).

Incidental learning also takes place in everyday experiences and learners are not commonly aware they have learnt (Marsick \& Watkins 2015, p.12). Incidental learning extends from concepts of social learning theory and experiential learning theory (Younes \& Asay 2003, p. 142). Social learning theory understands we learn from and with other people and this is predicated by our relationship with the teachers and between the learners themselves. 
There is also a social purpose for learning; to advance interests, raise awareness or improve effective participation in society (Jarvis, Griffin \& Holford 2003, p. 37). Experiential learning is, quite simply, learning from experience where learners actively construct their own learning experience within a social and cultural context. It can also be defined as the process through which individuals transform experience into knowledge, skills, attitudes, values and beliefs (Jarvis, Griffin \& Holford 2003, p.46). 'Experiential education breaks down any classroom and non-classroom distinction' (Hull 1981, p. 65).

Public pedagogy, on the other hand, refers to the forms, processes and sites of pedagogy happening outside of the formal schooling system (Sandlin, O’Malley \& Burdick 2011; Sandlin, Wright \& Clark 2013, p. 4). It is a field of research with broad areas of investigation that examines the educative force of libraries and museums, media, popular culture, commercial spaces, society and the diverse ways in which culture functions as an educative entity (Biesta 2013). Learning can occur anywhere at any time and is determined by the physical setting, the social interactions, personal beliefs, existing knowledge and attitudes of the person. This may include devices that send messages to individuals through television, movies, games, books and magazines; or spaces that shape a person or are locations of learning such as the home, family and community. In addition to this, activist sites and social movements fit the framework of public learning as all hold an educative responsibility beyond traditional schooling, impacting adults, community and popular culture, by influencing outlook and opinions (Sandlin, Schultz \& Burdick 2010, p. 14). Dentith and Brady (1998) state public pedagogy is a grassroots and community based occurrence, encouraging concrete advancement in neighbourhoods, health and social services.

Public pedagogy is an area of investigation that 'opens a space for contesting conventional academic boundaries and raises questions about the capacity for citizens to engage as critical educators in their present everyday lives' (2006, p. 58). This expansion of sites of learning from constrained classroom boundaries to public and private domains presents a new territory of the space between theory and practice, encouraging social action and working together for a common good. It also challenges concepts of who the educator is and who is being educated. Learning leadership, therefore, can transfer from formally recognized constructs to cultural activists, individuals and community groups. In addition, there are no clear definitions of the term public or of the boundaries that separate the idea of public from the private. The public, for instance, does not exist without private citizenship (Roberts \& Steiner 2010, p.21). Savage posits that the term public in public pedagogy refers to the accessible general population; those citizens who either by choice or through incidental exposure are able to consume what is available to them (Savage 2010, p. 106).

Sitting at the intersection of formal institutional learning and informal learning are study abroad programs. In some contexts, study abroad programs may be called education abroad, learning abroad, international learning mobility, outbound mobility, or student exchange, however in this article the term study abroad program will be used. A study abroad program is a form of experiential learning where students spend a portion of their academic year in a different country while remaining enrolled and receiving credit toward a degree at their home institution. They sit within the framework of overseas program options available to students, short or long term, and generally contain a rigorous academic content overseen by teachers and professors to ensure quality and transferability. 'Around the world, higher education institutions and governments are developing new policy goals to internationalize student learning by promoting learning abroad and increasing access to funding to support participation' (Potts 2015, p. 442). 
Study abroad programs produce a tension between abstract conceptualization (theory) and experience (practice) (Shin Yu, Harris \& Sumner 2006, p. 56) presenting a means for students to learn by doing (Howard \& Gulawani 2014, p. 104). Kutner (2010) recognizes university based study-abroad programs now include a focus on project-based and service-learning activities intended to directly benefit to their host countries. Learning which takes place on a study abroad program is identified as 'more natural', often unconscious, and contains a mix of experiential and situational learning (Shin Yu, Harris \& Sumner 2006, p. 56). To expand on this further, experiential learning is defined by teaching a person to participate in the process that makes possible the learning rather than by achieving predetermined outcomes (Bruner 1968, p.7 2). Learning is 'grounded in experience, and knowledge is continuously derived from and tested in the experiences of the learners'(Shin Yu, Harris \& Sumner 2006, p. 56). Situational learning is defined as a form of learning through participation in communities of practice and results from the activities, context and culture in which it is occurs (Shin Yu, Harris \& Sumner 2006, p. 56).

The intersecting and overlapping nature of institutional learning and public pedagogy is exposed when examining the case study of the Kelabit Highland Community Museum project, situated in Bario, the highlands of Borneo. This study abroad program, created to directly benefit the host community, also serves as an agent for change through project-based learning that benefits all participants; students, academics and community members. $\mathrm{Nu}-$ merous examples of informal learning can be identified in the complexity of the project outlined below. However, of significance was the continued learning that occurred in the community once the Deakin University group returned to their home location.

\section{The Kelabit Highlands Community Museum Study Abroad Program as a Site of Public Pedagogy}

The Kelabit Highlands Community Museum project was initiated by the Kelabit people's strong sense of need to preserve their cultural heritage. This understanding was bought on by an awakening of how their traditional tangible and intangible knowledge is being lost in the transformation of the Kelabit people by progress and could be preserved by the development of their own community museum. Although one of the smallest Indigenous groups in the Sarawak region numbering approximately 6,000 people, the Kelabit community has become renowned for their economic and professional accomplishments (Amster \& Lindquist 2005, p. 5). They are well educated and have come to understand how marketing, tourism and education can contribute to their own development goals. The aim of the Kelabit Highlands Community Museum project is to provide the opportunity for the Kelabit community to assert their authority over the representation and commodification of heritage and associated knowledge of their region 'while also creating environs inclusive of new and diverse voices of expertise and authority' (Padmini 2010, p. 96).

Initially the Kelabit Highlands Community Museum project was developed as a result of discussions between the Kelabit community and Ms Jan Drew, an educational consultant based in Malaysia. Representatives of Rurum Kelabit Sarawak (RKS), the governing body of the Kelabit community, through Jan Drew, contacted Dr Jonathan Sweet and invited him to visit the region to discuss how a community museum may be achieved. The project related to Dr Sweet's cultural heritage research and development interests in the region. This led to an invitation to conduct a study abroad program in June 2012, with Dr Sweet leading a small team of Deakin University students to assess the feasibility of establishing a community museum in the Bario region (Sweet 2012). It was essential to determine the level of community 
support for the development and the process by which data collection and documentation of the community's interests and cultural assets could be managed.

The success of the first study abroad program led to subsequent community consultations and study abroad programs (Sweet \& Kelly 2013) that consequently reveal a number of examples of public pedagogy and 'natural' learning. This article will structure these examples using the framework established through the extensive work of Sandlin, O'Malley and Burdick (2011), each well-respected commentators of public pedagogy. Sandlin et al. mapped the authors and themes of public pedagogy scholarship from 1894-2010 to identify five categories of public pedagogy research. This structure can be used as a foundation for the demonstration of study abroad program learning outside of the institutional environment. These include:

(a) citizenship within and beyond schools, (b) popular culture and everyday life, (c) informal institutions and public spaces, (d) dominant cultural discourse, and (e) public intellectualism and school activism (Sandlin, O’Malley \& Burdick 2011, p. 340).

This article will not recreate the work of Sandlin et al. but instead will draw on the concepts most relevant to the discussion. Working through each category, with demonstrated examples of how the study abroad program for the Kelabit Highlands Community Museum project acts as a site of public pedagogy, it becomes apparent there is great diversity and complexity to the informal learning that is evident. The examples described below are not the only examples that may be considered in this discussion, however, they are the examples exemplifying the categories as defined by Sandlin et al.

The first category recognizes an education that aims to develop identity creation and sense of citizenship. Citizenship within and beyond schools recognises informal learning agencies as a resource for the development of cultural identities. Citizenship within the school may involve bringing public concepts from outside the formal teaching spaces to inside the classroom such as drawing on examples of popular culture in teaching or reflecting on the impact of popular culture on mainstream practices. Citizenship beyond the school may involve the learning as it occurs in the home, through families, peer groups, communities, media and other non-school groups. This can be seen in the role of family defining acceptable boundaries through to the cohesion of community dynamics (Sandlin, O'Malley \& Burdick 2011, p. 342-343).

The Kelabit community initiative to enhance their cultural and social responsibility through the clearly defined aims of the community museum development demonstrates citizenship learning within and beyond the school. The community sought the assistance of advisors, who in this instance were external to the community, to inform and recommend a process to preserve their cultural heritage. Deakin University student and academic participants very quickly had to learn the customs, rules and understand the boundaries of the community expectations. As welcomed members to the community, students were expected to participate fully and respectfully in activities even if those activities were sometimes challenging to their cultural understanding. Learning for all participants came from specific discussions of cultural heritage and Indigenous knowledge, however, in addition, simple glances, quiet comments and gentle guidance between participants and community members would signal if someone had missed the cultural cues or moved beyond the acceptable boundaries of the community expectations. These cultural expectations were discussed in pre-departure meetings prior to the study abroad program, however, it is not until students and academics are immersed in the environment that they fully appreciate the citizenship responsibilities they are expected to follow. 
The second category of popular culture and everyday life intersects with the concepts of citizenship beyond the school to include the impact on learning of popular games, television and magazines. The progressive Kelabit community, well educated and engaged in all forms of popular culture, has identified through this transformation the need to preserve their traditional cultural heritage, yet wish to do so engaging with popular culture technologies. Yet they have experienced first hand how the power of the media and control of content creation overlaps with political discourse, raising the question of who controls the representation and how they control the dispersion of information. For the Kelabit community the definition of ethnic identity is complex: in law it is most sharply defined as 'native' but most are also practising Christians, a minority religion in the predominately Islamic Malaysian state. The location of their home village, Bario, close to the border of Kalimantan, further accentuates the perception that they passively exist on the peripheries of the modern Malaysian nation state, even though many Kelabit are active in contemporary Malaysian society.

Historically, the Kelabit have been represented in ways in which they have no real agency (Harris 2009, p. 131). The process of creating an environment to construct their cultural representation has empowered the community to contest their position in a complex Malaysian culture: 'By organizing collectively to challenge zero tolerance policies and replace them with community-determined alternative practices, community activists are discovering their power to contest state power' (Sandlin, Schultz \& Burdick 2010, p. 431). For this reason the focus of the Kelabit Highlands Community Museum involves the community's choice of media and imagery, and the surrounding communication strategies to construct and take ownership of the desired representation of Kelabit lifestyle and community values. Each touch point of visitor engagement with Kelabit identity aims to support the representation as identified by the collective community members. Moreover, a priority is to create the resources to develop a sense of social agency for future Kelabit community members as they respond to advancements with popular culture and its impact. Navigating this space and resultant representation is a process of ongoing evaluation and reevaluation through formal and informal community discussions as expectations are clarified.

The third category of informal institutes and public spaces as sites of public pedagogy includes research into other institutionalized sites of learning including museums, galleries, libraries and public parks. Learning in these spaces may be subtle, contained in an educational space within the public domain. Design plays a large role in this category of public pedagogy as 'these public spaces of display have been crafted toward an educational end, but one that is conscientiously decentered and improvisational, dependent on the learning subject as much as on the spaces' design' (Sandlin, O’Malley \& Burdick 2011, p. 349). Museums, in particular through their structure, content and exhibits, act as a symbolic communication device with a negotiated, agreed meaning. Understanding is drawn from the signs and symbol arrangements representing the public collective memory in a visual form.

The symbolic nature of communication was a central focus to the design based study abroad programs in this project. As an example, the design of the building and reflection upon the cultural values of the community, the focus of the architecture study abroad program, was a significant phase in the project development. Although only conceptual, the designs presented led to in-depth discussions of the signs and symbols that may be used to represent the Kelabit community and surrounding highlands. The architectural designs that were generated brought forward ideas not previously considered and opened discussion as participants debated the issues of project site, building requirements and structure.

The final museum conceptual design presented to the community paid strong homage and respect to Batu Lawi-the mountain peaks sighted upon entry to Bario region that plays 
an important role in the mythological and modern history of the region - and its surrounding natural environment. It captured the spirit of the local vernacular 'padi hut', the Lepoh and the essence of the Longhouse. As a result, the design concept was an amalgamation of Kelabit history, identity and culture, whilst at the same time delivered a vision for the future identity and connection to the younger generations of Kelabit community members, ensuring the building as a site of public pedagogy for future visitors.

The forth category identifies dominant cultural discourse as public pedagogy and is defined as how culture is taught and learned through public transmission of broadly communicated governmental, legal and medical discourse (Sandlin, O’Malley \& Burdick 2011, p. 352). Pedagogy is deeply rooted in constructs of power and authority, and in the organization of knowledge, desires, values and identities impacting teacher authority (Giroux 2004, p. 69). For this reason, dominant cultural discourse includes policymaking acting as a public pedagogy. 'Symbolic and institutional forms of culture and power are mutually entangled in constructing diverse identities, modes of political agency, and the social world itself' (Giroux 2004, p. 59).

The power structures are altered when a study abroad program is created to directly benefit the host community it serves. In this instance the dominant discourse and the driving influence of the Kelabit Highlands Community Museum project is derived from the governing body, the RKS, and the community itself. This was clearly evident when, in an attempt to structure ideas and concepts for the museum exhibition space, the academic team proposed, as a starting point to document the annual events of the community including farming, festival and seasonal happenings. This planned approach for gathering information was quickly proven to be not as the community wanted. Instead, the community changed the script, devised their own groupings and brainstormed their ideas in the manner they chose. The community initiated their own framework and through a process of trial and error, emerged with a number of ways to look at the content structure. Significant progress was made as community representatives identified key moments in history, debated the impact of these evolutions, drew diagrams of change and advancements made in the community and charted the impact this had on the governance, living and economic considerations of the region. The power remained in the hands of the community who respectfully determined the direction of the meetings.

\section{The Positive Impact of Collective Agency through Public Pedagogy}

Finally, and of significance to a project-based, on location, study abroad program, is public intellectualism and social activism. The project, being the creation of a community museum, involved 'public intellectuals as academics or other individuals in positions of cultural or economic power, with the capacity to translate social issues for a public audience and the public good' (Sandlin, O’Malley \& Burdick 2011, p. 354). This served as a motivation of all participants who were endeavoring to explore collective agency to achieve the desired result of a sustainable community museum to generate income for a remote region in Borneo. The aim of academics disseminating knowledge to the general public for a set purpose is linked to the concepts of social change with the view that a public educated with appropriate knowledge will influence the public towards collective change.

Giroux, a dominant figure in the development of the term public pedagogy (Sandlin, Schultz \& Burdick 2010, p. 2), analyses the intersection of cultural studies and education. Giroux introduced the notion of public intellectuals based on the idea that academic intelligentsia have the opportunity to educate the public and disseminate expert knowledge to the general public for public good (Sandlin, O’Malley \& Burdick 2011, p. 355). Giroux argues it is the obligation of intellectuals to be open to communities and connect the education en- 
vironment with the community by communicating in a language that is understood by the general public (Giroux 2004, p. 71). In short, intellectuals should connect their theories to practice and make them valuable to the general public. This premise links democracy with social change, distributing knowledge for the purpose of public adoption of ideas. This may be through a transformative engagement addressing a social problem, a process of critical change or in the instance of the Kelabit Highlands Community Museum project, a means of empowering a community to make decisions.

The concept of public intellectualism and social activism is a topic of debate in academic literature. On the one hand, Whitlock (2010, p. 461) argues the two concepts, theory and practice, cannot be combined as Giroux proposes, and instead they argue theory will remain a thinking process written and documented while practice will be practice. Whitlock suggests intellectuals do their thinking mindful of the impact this may have on the everyday lives of people and the potential for their agency. On the other hand, and taking an extremely positive approach, Curtis talks inspirationally of the need for universities to revise pedagogy and 'embracing the task of creating hands-on learning around civic agency' (2012, p. 359). This would create a culture where participants believe change is possible and communities understand their ability to craft change. Having intellectuals construct an environment where community organizing is encouraged, challenges the usual flow of teaching and learning so that the learning dynamics are interactive. Curtis identifies that mutual learning generates a sense of hopefulness in collective action and shared responsibility, moving people away from a sense of isolation and privacy. This article argues a study abroad program focused on project-based activities intended to directly benefit the host community can also be seen as a positive engagement with hands-on learning aimed at civic agency. The intersection of theory with practice, the active problem solving and the transparent intent of generating change for a community is a powerfully positive experience for all participants.

Significant to the success of the project was the extensive participation and involvement of the community and consequently this research relies on the concepts of collective community agency for the project to be sustainable. Ahearn takes the position that agency is defined as the 'socioculturally mediated capacity to act' (2001, p. 112) but acknowledges this definition is open to interpretation leaving many details unspecified. Ahearn also addresses narratives of agency (2001, p. 128-129) in relation to place making and identifies the ability of creating empowerment through linguistic exchange using words and texts that are socially and geographically situated. These notions of agency are strongly aligned with the Kelabit Highlands Community Museum project where 'interpreting events, establishing facts, conveying opinion, and constituting interpretations as knowledge are all activities involving socially situated participants, who are agents in the construction of knowledge and agents when they act on what they have come to know, believe, suspect, or opine' (Hill \& Irvine 1993, p. 2). Lave and Wenger (1991) refer to the term 'community of practice' to define a group of people who come together around an agreed endeavour. Seen as different from a traditional construct of community, a community of practice is defined by a sense of purpose and by the practice in which that community shares mutual engagement.

The Kelabit Highlands Community Museum project can be defined as a project exemplifying collective agency and communities of practice. For each study abroad program, the methodology of participatory action research was followed; a methodology for change and development and an approach that integrates social investigation, education and action with the sole aim to support the Kelabit community in their development. It is an iterative process, whereby enquiry leads to action, which leads to a reflection on the action and opens a new line of enquiry (Greenwood \& Levin 2003, p. 149). 'At its most participatory, researchers 
engage with participants as collaborators who can inform project design, propose methods, facilitate some of the project activities, and importantly review and evaluate the process as a whole' (Mackenzie et al. 2012, p. 12). It is a research methodology known for its intent to integrate research into practice, inclusive of the diversity of participants, to ensure agreement with both the process and findings. With this in mind, participatory action research ensures the research activity responds to the needs of the stakeholders as it provides options to address real world problems (Mackenzie et al. 2012, p. 13).

In the case of the Kelabit Highlands Community Museum development, having originated in the community, this project has been defined by the community, and is analysed and solved by the community (Hall 2001, p. 175). The Deakin University academic and student teams proposed ideas to the Kelabit community who subsequently, once the academics and students had left, collectively decided on the best course of action. As an example, having offered ideas for the building structure based on community consultation, the community progressed and, at the time of publication, started construction on the museum building in Bario. The design of this building is a modified version of the two-roof structure proposed by the architecture students, taking reference from the mountains, Batu Lawi. The community took into consideration the intangible heritage of the region such as performance and craft activities, and considered the opportunities for expansion in the future, also as proposed by the students. The community consultations and drafts of the proposed structure were used as a learning tool by the community to create the design of the building in the revised location. There was a direct connection between the consultation process, the ideas presented and the culturally specific revised design created by the community and enacted by the community. The academics took the role of intellectuals empowering the Kelabit community to make decisions and collectively the community are agents in their construction of knowledge to enact social change.

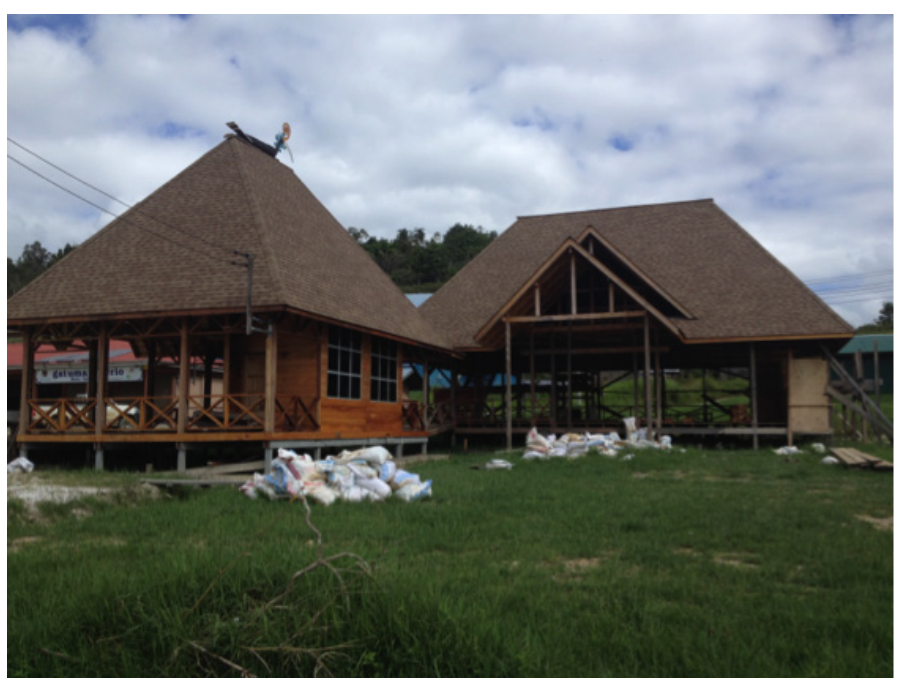

Image 1: Kelabit Highlands Community Museum building under construction, Bario, December 2015 (Kelly, 2015)

\section{Conclusion}

At the intersection of formal and informal learning are study abroad programs. The case study of the Kelabit Highlands Community Museum project highlights the depth and diversity of public pedagogy that occurs in a project-based, service driven program intended to directly benefit the host country. Reflecting upon the five categories established by Sandlin, 
O'Malley and Burdick (2011), the learning varied from simple, informal guidance through non-verbal signals for students to adhere to culturally accepted behaviours, to the collective activity to manage and control the representation and identity of this small Indigenous group. The formal structures established by the governing body of the Kelabit community, RKS, drove the policies and direction of the project, while the museum construct itself, acts as a communicative device to visitors and community members.

In addition, designs presented to the community demonstrated options of how the museum may be constructed and function. In essence, the study abroad program offered the community ideas for them to discuss, adapt and learn from to guide their decision making. The community, empowered by the academic and student visits, collectively made decisions regarding how to progress the development and as a result, a grand building is under construction in the central township of Bario. The student and academic participants facilitated the community's own agency in learning as much as they were able to learn themselves. For this reason, the Kelabit Highlands Community Museum project is a significant example of informal learning derived from formal learning, demonstrating how study abroad programs in practice serve as a catalyst for collective agency in positive change.

\section{References}

Ahearn, L 2001, 'Language and agency', Annual Review of Anthropology, vol. 30, pp. 109138.

Amster, M \& Lindquist, J 2005, 'Frontiers, Sovereignty, and Marital Tactics: Comparisons from the Borneo Highlands and the Indonesia-Malaysia-Singapore Growth Triangle', The Asia Pacific Journal of Anthropology, vol. 6, no. 1, pp. 1-17.

Biesta, G 2013, 'Making Pedagogy Public: For the Public, of the Public, or in the Interest of Publicness?', in J Burdick, J Sandlin \& M O'Malley (eds), Problematizing Public Pedagogy, Taylor and Francis, Hoboken, pp. 15-25.

Brady, J 2006, 'Public Pedagogy and Educational Leadership: Politically Engaged Scholarly Communities and Possibilities for Critical Engagement', Journal of Curriculum \& Pedagogy, vol. 3, no. 1, pp. 57-60.

Bruner, J 1968, Toward a theory of instruction, New York: Norton, 1968.

Curtis, K 2012, 'Creating a Culture of Possibility: A Case for Engaged Pedagogy', Humanity \& Society, vol. 36, no. 4, pp. 354-73.

Dentith, A \& Brady, J 1998, 'Girls on the strip: Constructing a critical feminist pedagogy of difference in Las Vegas', in American Educational Research Association on Women and Education SIG Conference, East Lansing, Michigan.

Giroux, H 2004, 'Cultural Studies, Public Pedagogy, and the Responsibility of Intellectuals', Communication \& Critical/Cultural Studies, vol. 1, no. 1, pp. 59-79.

Greenwood, D \& Levin, M 2003, 'The Relationships Between Universities and Society Through Action Research', in NK Denzin \& YS Lincoln (eds), The landscape of qualitative research : theories and issues / Norman K. Denzin, Yvonna S. Lincoln, editors, 2nd edn, Sage Publishing, Thousand Oaks, CA

Hall, B 2001, 'I wish this were a poem of practices of participatory research', in P Reason \& H Bradbury (eds), Handbook of Action Research, Sage Publishing, London. 
Harris, R 2009, 'Tourism in Bario, Sarawak, Malaysia: A case study of pro-poor community-based tourism integrated into community development', Asia Pacific Journal of Tourism Research, vol. 14, no. 2, pp. 125-35.

Hill, J \& Irvine, J 1993, Responsibility and evidence in oral discourse, Studies in the social and cultural foundations of language: no. 15, New York: Cambridge University Press, 1993.

Howard, K \& Gulawani, M 2014, 'Student Perceptions of Study Tour Learning: A Case Study', Aweshkar Research Journal, Prin. Welingkar Institute of Management Development \& Research, vol. 18, pp. 101-114.

Hull, W 1981, 'Cross-cultural experiential programming', International Review of Education, vol. 27, no. 1, pp. 64-75.

Jarvis, P, Griffin, C \& Holford, J 2003, The theory \& practice of learning (2nd ed), London; Sterling, Va.: Kogan Page.

Kutner, L 2010, 'Study-Abroad Programs as Information Producers: An Expanding Role for Support of Our Students Studying Abroad', Journal of Library Administration, vol. 50, no. 7-8, pp. 767-78.

Lave, J \& Wenger, E 1991, Situated learning: legitimate peripheral participation, Learning in doing, New York: Cambridge University Press, 1991.

Mackenzie, J, Tan, P, Hoverman, S \& Baldwin, C 2012, 'The value and limitations of Participatory Action Research methodology', Journal of Hydrology, vol. 474, pp. 11-21.

Marsick, VJ \& Watkins, KE 2015, Informal and incidental learning in the workplace, Routledge, New York.

Padmini, S 2010, 'Representation and relevance: multiple narratives in immigration museums', in G Rouette \& Museums Australia (Victoria) (eds), Exhibition design for galleries and museums: an insider's view, Museums Australia, Carlton South, Vic.

Potts, D 2015, 'Understanding the Early Career Benefits of Learning Abroad Programs', Journal of Studies in International Education, vol. 19, no. 5, pp. 441-59.

Roberts, PA \& Steiner, DJ 2010, 'Critical Public Pedagogy and the Paidagogos: Exploring the Normative and Political Challenges of Radical Democracy', in JA Sandlin, BD Schultz \& J Burdick (eds), Handbook of public pedagogy: Education and learning beyond schooling, Routledge, New York, pp. 20-7.

Sandlin, JA, O’Malley, MP \& Burdick, J 2011, 'Mapping the Complexity of Public Pedagogy Scholarship: 1894-2010', no. 3, p. 338.

Sandlin, JA, Schultz, BD \& Burdick, J 2010, Handbook of public pedagogy: Education and learning beyond schooling, Routledge, New York.

Sandlin, JA, Wright, RR \& Clark, C 2013, 'Reexamining Theories of Adult Learning and Adult Development Through the Lenses of Public Pedagogy', Adult Education Quarterly, vol. 63, no. 1, pp. 3-23.

Savage, GC 2010, 'Problematizing "Public Pedagogy” in Educational Reserach', in JA Sandlin, BD Schultz \& J Burdick (eds), Handbook of public pedagogy: Education and learning beyond schooling, Routledge, New York, pp. 103-15. 
Shin Yu, M, Harris, R \& Sumner, R 2006, 'Exploring Learning during Study Tours', International Journal of Learning, vol. 12, no. 11, pp. 55-62.

Sweet, J 2012, 'Museum development and cross-cultural learning in the Kelabit Highlands, Borneo', Museums Australia Magazine, vol. 21, no. 1, pp. 23-6.

Sweet, J \& Kelly, M 2013, 'Consultation unlocks interdisciplinary resources: A community museum evolving in the Kelabit Highlands, Malaysian Borneo', Museums Australia Magazine, vol. 22, no. 2, pp. 27-9.

Whitlock, RU 2010, 'In My Father's House, or Public Pedagogy and the Making of a Public “interleckchul”, in JA Sandlin, BD Shultz \& J Burdick (eds), Handbook of Public Pedagogy: Education and Learning Beyond Schooling, Routledge, New York, pp. 456-68.

Younes, MN \& Asay, SM 2003, 'The world as a classroom - the impact of international study experiences on college students', College Teaching, vol. 51, no. 4.

\section{Images}

Image 1: Kelly, M 2015, Kelabit Highlands Community Museum building under construction, Bario, Borneo, December 2015, photograph taken by the author.

\section{About the Author}

Dr. Meghan Kelly is a visual communication designer whose experience includes the advertising and design industries and running her own design studio. Kelly has also been teaching design for over 20 years and currently serves as the Associate Head of School (Teaching and Learning) for the School of Communication and Creative Arts and a senior lecturer in Visual Communication Design at Deakin University, Melbourne, Australia. She completed her $\mathrm{PhD}$ examining cross-cultural visual communication design with an interest in exploring issues surrounding identity creation and representation in a cross-cultural context. Her passion for a global understanding of design extends into her teaching and continues to be explored in research projects and design opportunities exploring the intersection of public pedagogy and design practice.

Dr. Meghan Kelly

School of Communication and Creative Arts

Deakin University, Melbourne

meghan.kelly@deakin.edu.au 